\title{
Stephanie Louise Kwolek - Kevlar, a Fibra à Prova de Bala
}

Raquel Gonçalves Maia

\begin{abstract}
Stephanie Louise Kwolek - Kevlar, the bulletproof fiber. Stephanie Kwolek was an American chemist who, working in DuPont research labs, discovered a synthetic polymer, an aramid, stronger and lighter than steel and bulletproof - Kevlar. "Saved by Kevlar", it's been a miracle for thousands of lives. She was born to Polish immigrants in New Kensington (Pennsylvania) and graduated from Carnegie Institute of Technology. At DuPont, she has also contributed largely to the development of low temperature polymerization processes. Her paper "The Nylon Rope Trick" is still a key piece for a common science classroom experiment. Kwolek's story - her childhood, achievements and works - is the story of a woman's life devoted entirely to chemistry.
\end{abstract}

Stephanie Kwolek foi uma química norte-americana que, a trabalhar nos laboratórios de investigação da DuPont, descobriu um polímero sintético, uma aramida, mais forte e mais leve do que o aço e à prova de bala - o Kevlar. "Salvo pelo Kevlar", tem sido um milagre para milhares de vidas. Filha de pais emigrantes polacos, Kwolek nasceu em New Kensington (Pensilvânia) e graduou-se pelo Carnegie Institute of Technology. Na DuPont, muito contribuiu também para o desenvolvimento de processos de polimerização a baixa temperatura. O seu artigo "The Nylon Rope Trick" é ainda hoje peça fundamental na experiência em sala de aula. A história de Kwolek - a sua infância, as suas conquistas, os seus trabalhos - é a história da vida de uma mulher inteiramente dedicada à química.
Quando, em 1964, Stephanie Kwolek iniciou investigação sobre a procura de novas fibras resistentes e rígidas estava longe de saber que se tornaria numa supermulher. De facto, Kwolek, com o seu escasso metro e meio, inventou uma fibra mais forte do que o aço, "à prova de bala" - o Kevlar [1-3].

\section{Da Polónia para os EUA}

Nascida no seio de uma família humilde, em 31 de julho de 1923, Stephanie (Stefania) Louise Kwolek, veio a ter um irmão Stephen (Stanislaw), dois anos mais novo, Stefi e Stas, em família. Os pais, Aniela (Nellie) Zajdel e Jan (John) Kwolek, tinham nascido na região de Krosno, uma bonita província implantada no sudeste florestal da Polónia. Tal como muitos habitantes locais, também eles emigraram para os EUA, ainda muito jovens, em fuga à pobreza. 0 encontro e o casamento tiveram lugar na "terra das oportunidades" e os dois filhos vieram ao mundo em New Kensington (Pensilvânia).

John Kwolek, amador convicto da Natureza, era moldador numa pequena fundição local. Morreu cedo, com pouco mais de quarenta anos, em consequência de uma pneumonia num pós-operatório a uma hér-

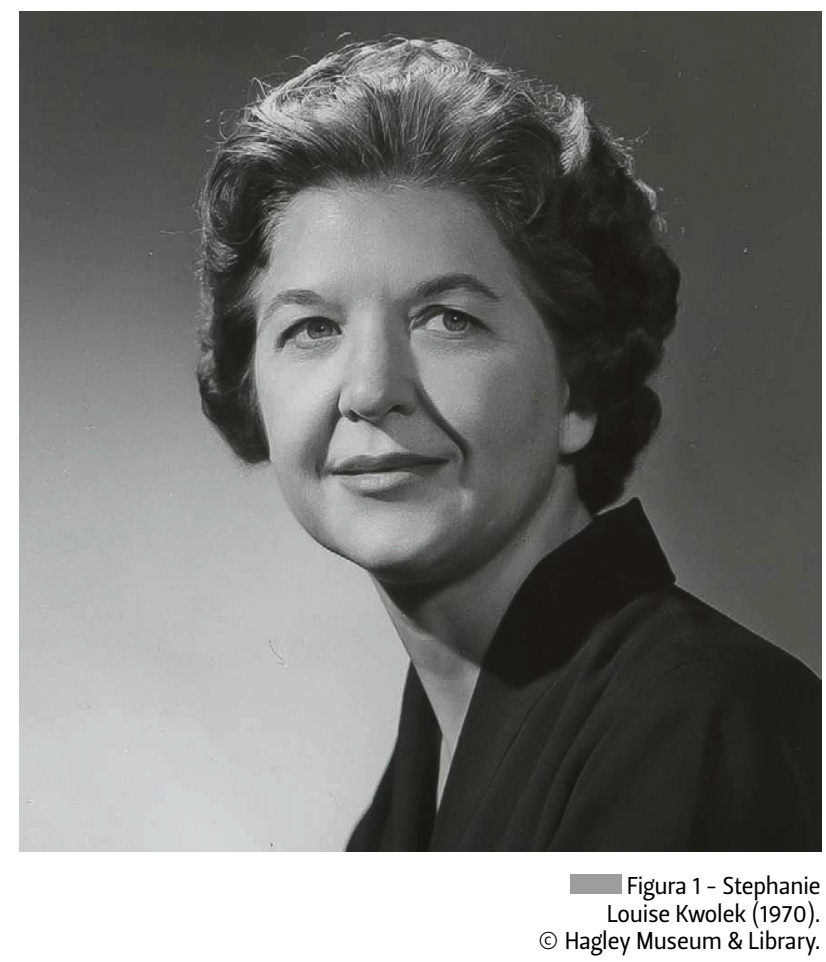




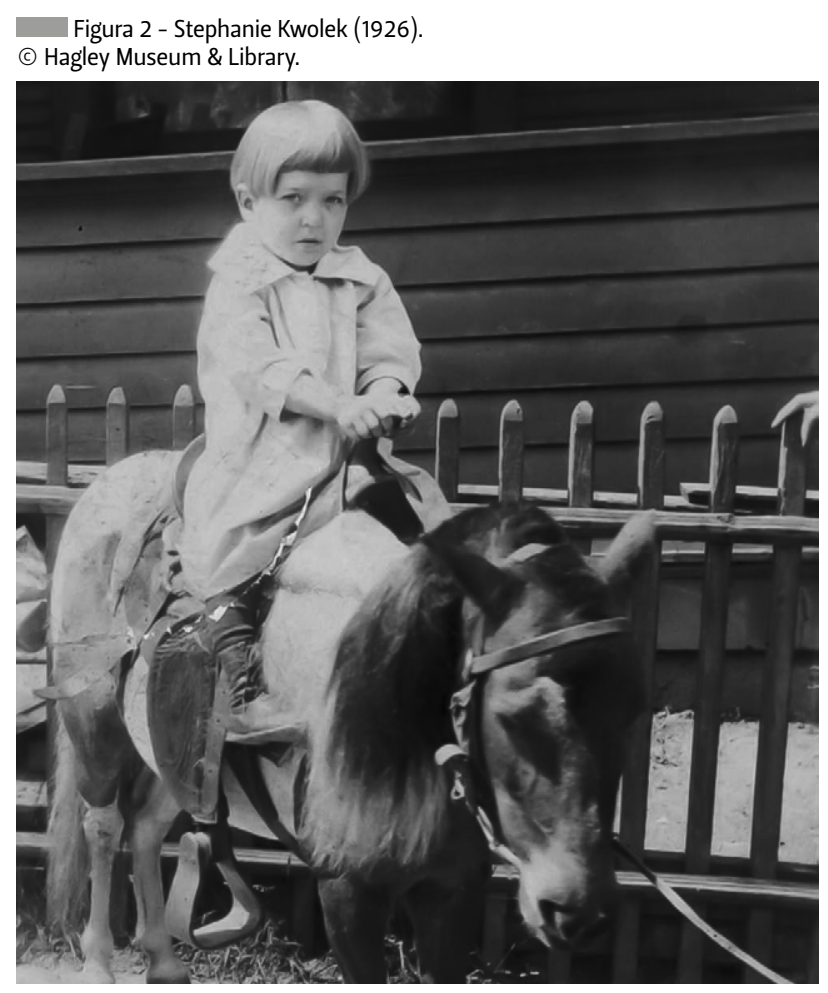

nia. Stephanie tinha 10 anos. Nellie, nove anos mais nova que o marido, costurava em casa, mas veio a empregar-se na Aluminium Company of America, no departamento de produção de utensílios culinários, a fim de poder sustentar a família. Apesar das dificuldades financeiras, ambos os filhos estudaram no Carnegie Institute of Technology, uma escola de engenharia que veio a integrar a Universidade Carnegie Mellon (Pittsburgh, Pensilvânia) [4].

Stephanie era muito boa aluna, gostava de ciências da natureza e de matemática, explorava a fauna e a flora dos bosques e dos riachos circundantes, sempre acompanhada do irmão, e alimentava o desejo de ser estilista nos múltiplos vestidos que desenhava para as suas bonecas; ou então professora, função que sempre desempenhava com as crianças suas vizinhas. Gostava de ler e de escrever. Para memória ficou a sua fotografia aos 3 anos montada num pónei e um desenho a decorar uma carta de Natal enviada em 1928 ao seu avô paterno na Polónia [3].

\section{Do Margaret Morrison Carnegie College para a DuPont}

0 Margaret Morrison Carnegie College, fundado em 1903, era o College para raparigas do Carnegie Institute of Technology. A educação primava pelo rigor e, em tempo da Segunda Guerra Mundial, o seu cunho era marcadamente feminista - não ter medo de falar no que se acreditava ser certo e exigir excelência em tudo o que se fazia.
Bolsas de estudo, pelo seu elevado nível académico, e trabalho de férias custeavam agora os estudos de Stephanie. Durante o verão, trabalhou nos laboratórios da Escola de Bioquímica da Universidade de Pittsburgh, dedicados à investigação de porfirinas, e no laboratório de investigaç̧ão da empresa Golf Oil em Harmarville, em estudos de fracionamento de derivados do petróleo que envolviam avançados cálculos matemáticos.

Em 1946, Stephanie Kwolek sai do Carnegie Institute of Technology empunhando o seu canudo de "bachelor of science", BSc., especializada em química (major) e em biologia (minor). No seu horizonte está agora o curso de medicina; mas, para já não pode pagá-lo, teria de economizar primeiro...

Ao tempo, a DuPont (E. I. DuPont de Nemours and Company) tinha em William Hale Charch (1898-1958), cientista que revolucionara a produção do celofane em 1927, um dinâmico entrevistador de potenciais químicos para integrarem a empresa. Kwolek não hesitou.

Acrescente-se que no pós-guerra muitos empregos, antes prioritariamente para homens, estavam agora abertos a mulheres. A DuPont foi pioneira neste domínio. Escasseava a mão de obra masculina qualificada e as raparigas tinham tomado de assalto a universidade.

A entrevista correu bem. Hale Charch ficou agradado e assegurou a Kwolek que o resultado Ihe seria comunicado "dentro de poucas semanas". "Será que não me poderia dizer antes, outras empresas esperam a minha resposta...", arriscou Sephanie. Era verdade, mas também era verdade que o trabalho na DuPont era o que mais a seduzia e a empresa, ao contrário de muitas outras, pagava salários iguais para iniciados de ambos os sexos [5]. No instante seguinte foi-Ihe oferecido emprego - no laboratório de investigação do Textile Fibers Department da DuPont [6], em Buffalo, Nova lorque, laboratório onde eram ensaiadas as primeiras pesquisas!

Não era comum que a empresa contratasse químicos apenas com o grau BSc. Alguns fatores foram decisivos: a forma resoluta como Kwolek se apresentou, a par com as suas notas excelentes [7] e a prática laboratorial prévia.

Tinham decorrido apenas oito anos desde que Wallace Carothers (1896-1937) criara para a DuPont o Nylon, a primeira fibra totalmente sintética [8]. A investigação e produção de novas fibras fervilhava de entusiasmo. Kwolek dirá que os seus primeiros anos de laboratório na DuPont foram "um desafio, uma constante aprendizagem". Trabalhou primeiro sob a orientação de Emerson L. Wittbecker em poliamidas, síntese de intermediários e de polímeros, depois, com Emmette K. Izard, o presumível inventor do poliéster Dacron, na preparação de intermediários suscetíveis de conduzirem à obtenção de novos poliésteres, e com 
Paul Winthrop Morgan (1911-1992) em derivados da celulose, películas e corantes $[9,10]$.

No bem equipado laboratório, Kwolek aprendeu a fazer longas moléculas que podiam ser transformadas em têxtil ou em plástico - matérias novas, que ainda não faziam parte dos currículos universitários.

"Estava tão interessada na química e na investigação que esqueci totalmente a medicina", afirmou Stephanie Kwolek anos mais tarde. E, para mais, Buffalo era socialmente atraente. Mas estava-Ihe destinada uma grande mudança.

A instalação de investigação e desenvolvimento da divisão de fibras têxteis da DuPont, o Pioneering Research Laboratory, que fora fundado em 1935 em Buffalo, muda-se para Wilmington, Delaware, como extensão da famosa Experimental Station em 1951[11].

Stephanie Kwolek retarda ao máximo a sua transferência para Wilmington. Parte em 1954. "Foi um momento triste e de grande incerteza para mim", dirá Kwolek [1]. Ninguém adivinha o futuro, mas para ela foi o momento em que principiou a sua verdadeira exploração.

\section{Polimerização a baixa temperatura}

Em 1986 Stephanie Kwolek foi protagonista de uma longa e didática conversa com o seu colega Raymond C. Ferguson, cientista versátil, desde a espectroscopia molecular até à caracterização de polímeros. Quando confrontada com a questão de quais considerava serem as suas contribuições mais signnificativas para a ciência química, respondeu que, "em segundo lugar", tinha sido "a descoberta e o desenvolvimento, em colaboração, de processos de polimerização a baixa temperatura para preparação de poliamidas aromáticas e outros polímeros de condensação" e de adição, homo- e copolímeros [1].

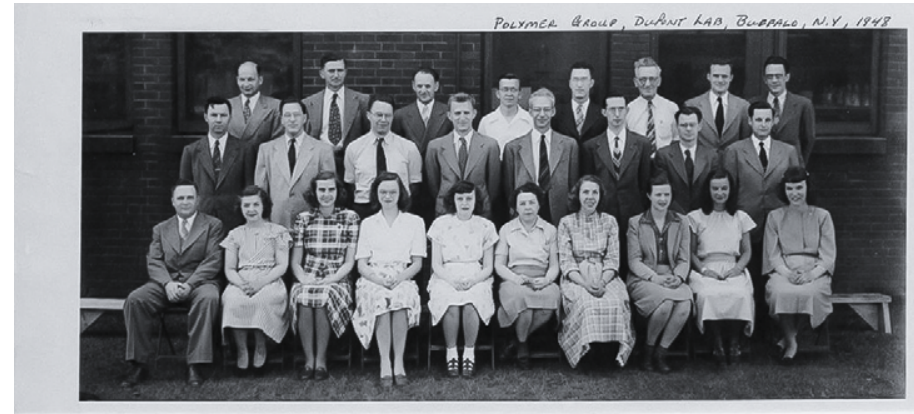

R. Houtz, E. Iłzard, P. Morgan, G. Rothrock, D. Green, E. Merlraith, R. Beaman, H. Mighton (Tof Row) F. Signaigo, J. Flanigan, E. Blaisdell, J. Shivers, L. Ray, N. Higgins, L. Auspos, E. Wittbecker Snyder, S. Kwolek, B. Chase, Jeanne Boehmke, A. Wierzbowski, M. Godfrey, B. Paige, J. Dickinson,
M. A. Lyon, Ritz Wonsowicz

Figura 3 - Grupo dos Polímeros

Laboratório DuPont, Buffalo, Nova lorque, 1948 Da esquerda para a direita: Stephanie Kwolek, sentada, é a segunda; $E$. Wittbecker é o último na segunda fila e E. Izard e P. Morgan são

segundo e terceiro, respetivamente, na última fila. (c) Hagley Museum \& Library

Previamente, estes polímeros eram "intratáveis", não fundiam ou degradavam-se antes de fundirem. Emerson Wittbecker iniciara investigacção em 1950, tendo conseguido produzir um poliuretano por um método a baixa temperatura. Depois, já em Wilmington, Paul Morgan, Stephanie Kwolek e outros investigadores, em colaboração, conseguiram muito mais. Os novos métodos vieram permitir uma enorme expansão da produção de alguns produtos e alargar a oferta de muitos outros com interesse comercial e industrial. Nesta gama, são de referir a fibra acrílica Orlon (PAN - poliacrilonitrilo), a fibra sintética de elevada elasticidade Spandex-Lycra (essencialmente PU - poliuretano) e, particularmente, o Nomex (meta-aramida), leve e flexível, muito resistente ao fogo e isolante térmico e elétrico, ideal para equipamentos usados por bombeiros e militares.<smiles>CC(C)(C)CC(C#N)C(C)(C)C</smiles>

Orlon<smiles>CCCCNc1cccc(NC(=O)c2cccc(C(C)=O)c2)c1</smiles>

Nomex
Figura 4 - Estruturas básicas do Orlon, do Nomex e do Spandex-Lycra.

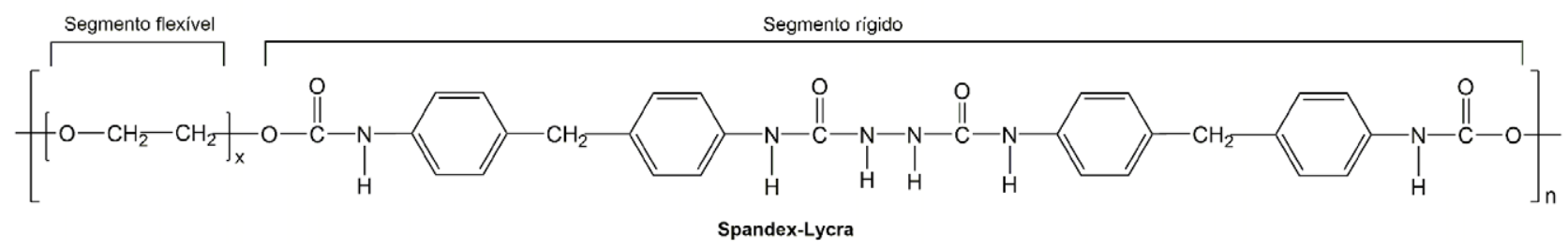


Mas a sua descoberta "em primeiro lugar" ainda estava por vir. Nos anos 60, Stephanie Kwolek sintetizou um novo polímero, leve, forte e rígido, com propriedades que o tornavam único. Veio a chamar-se Kevlar e o seu uso no fabrico de coletes à prova de bala já salvou milhares de vidas.

\section{Kevlar - um caso de acaso}

Em 1964, o grupo de investigação de Kwolek tinha pela frente um novo desafio. 0 desenvolvimento das tecnologias de transporte associado a um forte mercado consumidor tinham fomentado o crescimento da indústria do petróleo. Havia, porém, uma forte possibilidade deste "ouro negro" vir a escassear. Mas, se fosse possível reforçar os pneus de automóveis, aviões e outros veículos com uma fibra muito resistente, mas significativamente mais leve do que o arame de aço, os veículos teriam maior rendimento com menos combustível. Além disso, a fibra criada tinha de resistir a temperaturas muito elevadas, por evidentes questões de segurança.
Foram muitas as combinações de reagentes que Kwolek fez e os polímeros que obteve. A sua aposta centrava-se nos polímeros aromáticos. A sua experiência anterior e as características do Nomex assim o determinavam. Depois de sintetizados, fundidos e fiados eram submetidos a testes a fim de determinar o seu peso, robustez e estiramento e se tendiam a quebrar facilmente. Dois polímeros aromáticos mostraram-se promissores: não fundiam. Era preciso encontrar um solvente para eles. Um deles, produzido por reação da $p$-fenilenodiamina com cloreto de tereftaloílo [12], apresentou um comportamento estranho. Ao invés de uma comum solução algo pastosa, translúcida ou transparente, obteve uma semelhante a água turva. Ao centrifugar a solução separaram-se duas camadas. Uma amarela, límpida, e outra opalescente. Seria possível passá-la à fieira? Seria possível obter um fio? Facto era que, por filtração, tudo passava sem deixar rasto... "o fluxo certo e as propriedades de coesão desejáveis", disse-nos Kwolek, "fiou lindamente" [2]. Uma grande descoberta, com um potencial imediatamente reconhecível $[1,13]$. Corria o ano de 1965.<smiles>Nc1ccc(N)cc1</smiles>

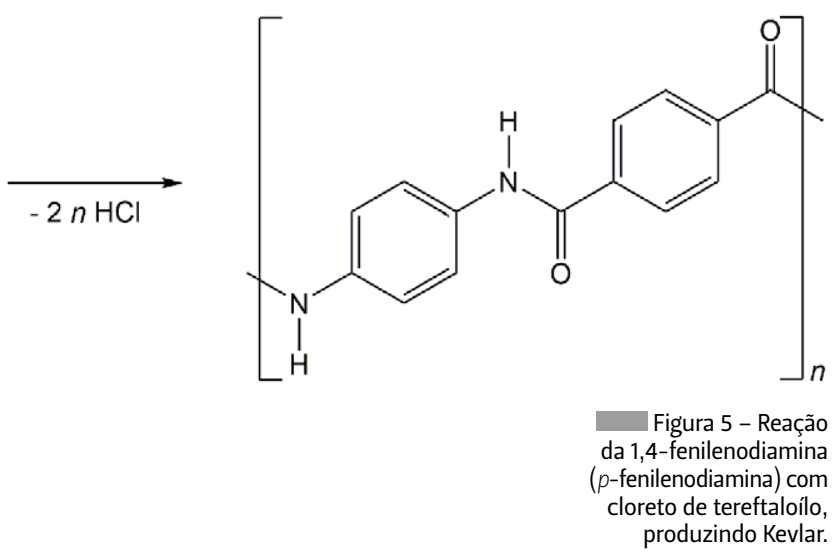

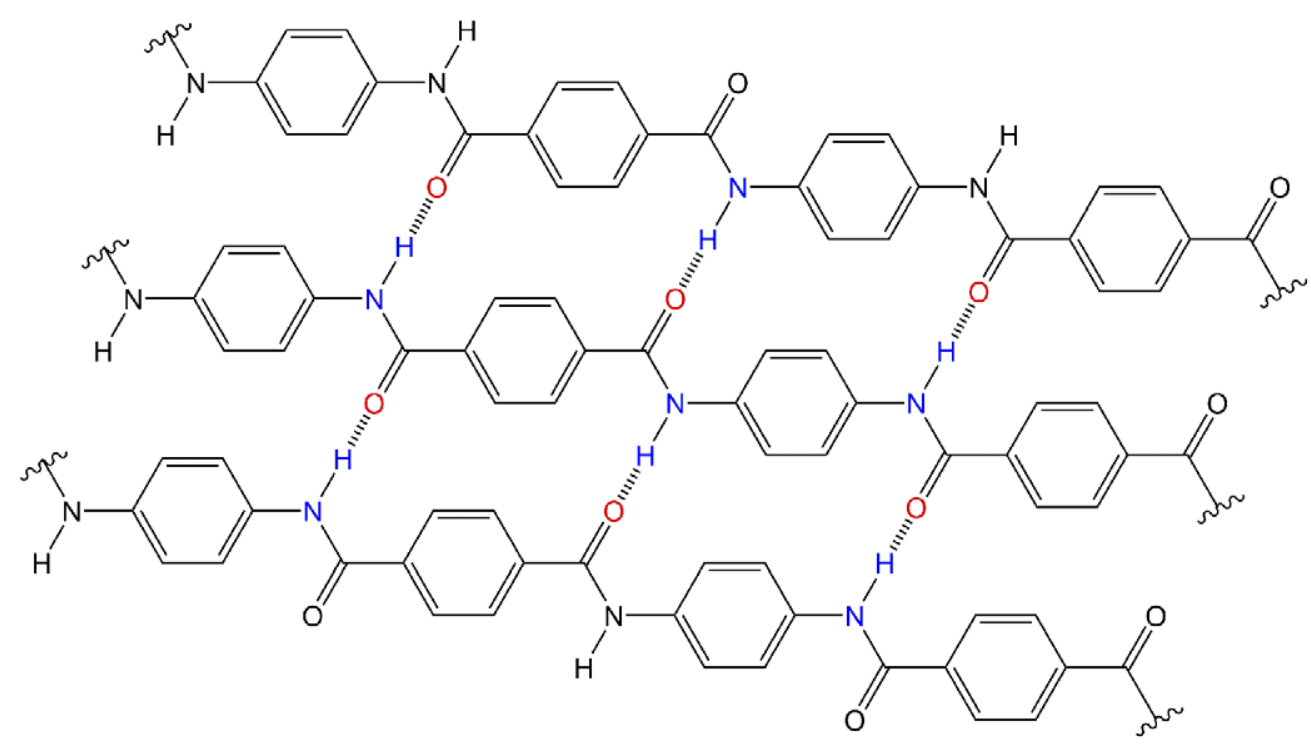


No Kevlar, as moléculas de p-fenilenotereftalamida são constituídas por grupos fenilo, planares, ligados por grupos amida. As cadeias apresentam uma conformação trans, linear e rígida. Dispostas em camadas, como planos cristalográficos, a sua estrutura é estabilizada por ligacções de hidrogénio entre as cadeias.

Seguiram-se os testes físicos. A nova fibra era muito forte e rígida, de uma enorme resistência ao calor e uma excelente prestação mecânica. A fibra aromática de poliamida, uma aramida, veio a chamar-se Kevlar. A sua descoberta foi, nas palavras de Stephanie Kwolek, "um caso de acaso...".

Foram vários os cientistas que ficaram associados a esta descoberta: Paul W. Morgan, Thomas (Tom) I. Bair, Joseph (Joe) L. Rivers, Jr. e Herbert (Herb) Blades [14]. Ninguém teve dúvidas quanto à inovação introduzida no domínio dos polímeros. Mas, uma coisa é a escala laboratorial, outra a industrial... Entre vários problemas, a fiação da fibra era tarefa extremamente exigente e delicada que, em grande escala, tornava a fibra inviável do ponto de vista económico. "Impossível, não se faz", disse o economista da DuPont chamado a intervir. Mas fez-se. Desde o momento da descoberta até à venda do produto obtido, todavia, foram dez anos de esforço conjunto de um grupo de investigadores. A comercialização do produto muito deve à intervenção científico-tecnológica de Herbert Blades. Em 1975, o Kevlar era, finalmente, introduzido no mercado. Entretanto, foram muitas as patentes produzidas e muito poucos os artigos científicos publicados - qualquer informação podia ser útil para um concorrente $[15,16]$. O secretismo domina o mundo da química industrial, todos o sabem.
Ao Kevlar original, o K29, outros se sucederam: K49, $100,119,129 .$. e outros polímeros de cristal líquido. Os polímeros de cristal líquido (Liquid-crystal polymers) - LCPs, são uma classe de polímeros aromáticos com características muito especiais. Estas superfibras apresentam alta resistência mecânica a temperaturas elevadas, são praticamente inertes à ação de produtos químicos (ácidos e bases fortes, cetonas e agressivos industriais), à chama e às intempéries. São estáveis em água fervente. Leves, mais leves e resistentes do que o aço! A sua aplicação primeira é, sem dúvida, em coletes, capacetes e luvas à prova de bala. Mas são também muito utilizadas em aplicações aeroespaciais e militares, na fabricação de peças de compósitos e como um substituto do asbesto (amianto). São vários os componentes do space shuttle, o vaivém espacial, que usaram Kevlar. E os cabos de suspensão das pontes. E as raquetes de ténis, canoas e skis. E os recipientes de gasolina dos carros de Fórmula 1. E...

\section{O truque da corda de nylon}

Como quase todos os químicos industriais, Stephanie Kwolek não é muito conhecida, mesmo entre os profissionais da química, em grande parte pelo secretismo atrás invocado. 0 artigo de Kwolek, em colaboração com Paul Morgan, mais citado foi publicado no Journal of Chemical Education, com o título "The nylon rope trick: Demonstration of condensation polymerization" [17]. Nele, os autores descrevem como um professor pode mostrar a polimerização por condensação aos seus jovens alunos, com pouco mais do que um gobelet, à pressão atmosférica e à temperatura ambiente - uma motivante experiência de introdução aos polímeros. Desde então, o ensaio tem sido efetivado em múltiplas escolas não só nos EUA, mas em todo mundo.

\footnotetext{
Figura 7 - Stephanie Kwolek e investigadores do grupo DuPont do Kevlar Da esquerda para a direita: Herbert Blades, Paul Morgan e Joseph Rivers Jr.
} Oferta de Stephanie Kwolek. ( DuPont

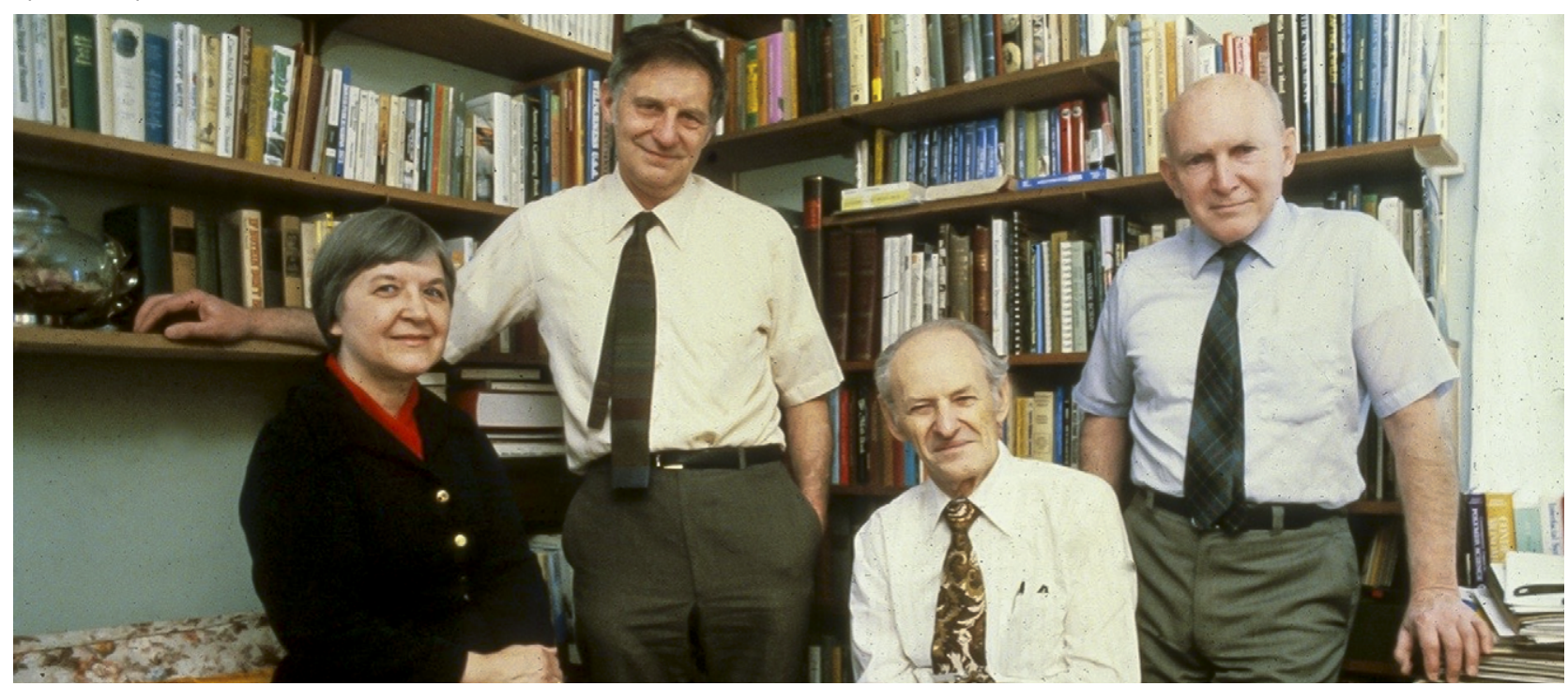


Figura 8 - Síntese do nylon 6,10.

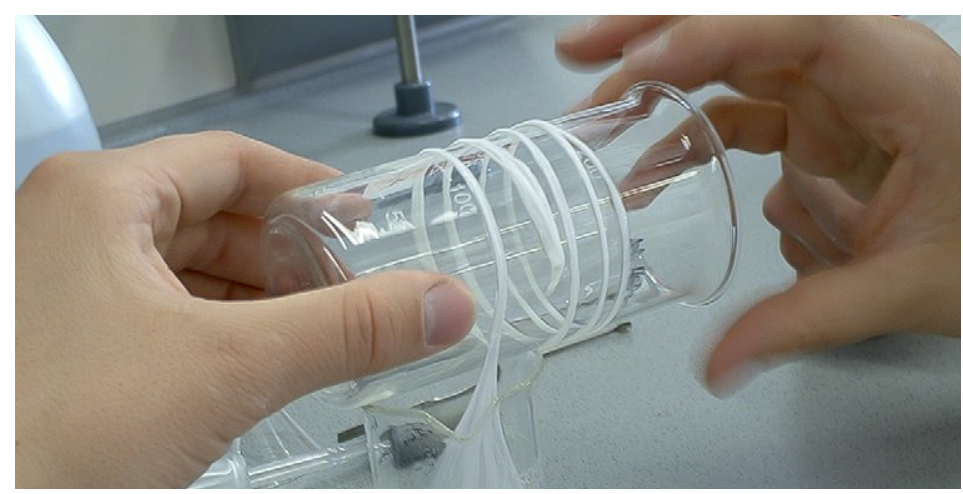

(2)<smiles>CC(O)CCCCCCCCC(=O)NCCCCCCN(C)C(C)C</smiles>

\section{Afundar ou nadar}

Stephanie Kwolek era uma criança muito viva, que saltitava durante os mais de $3 \mathrm{~km}$ ida e volta, casa escola. No entanto, tinha um defeito na estrutura óssea de uma perna, possivelmente de origem genética, e ainda muito jovem teve de ser submetida a uma complicada operação cirúrgica; e, anos mais tarde, sofreu operação a um joelho. Desde cedo que Kwolek compreendeu que viver era "sink or swim", "afundar ou nadar", lema que conservou durante toda a vida.

Os tempos de estada de Stephanie Kwolek em Buffalo foram tempos de grande aprendizagem científica, mas também de descoberta pessoal. Kwolek era jovem e dinâmica. Rapidamente fez de colegas amigos e juntou mais alguns que frequentavam como ela as igrejas católica e presbiteriana. As atividades sociais e culturais preenchiam os seus fins de semana, sempre em alegre companhia: as caminhadas, a natação, o esqui, a patinagem, os piqueniques... e uns passos de dança - uma vida risonha e saudável. A partida para Wilmington foi de decisão difícil, para mais quando Kwolek antevia um casamento para sempre adiado.

Em termos culturais a transição foi um choque. Ao tempo, Buffalo era uma cidade com uma boa oferta de galerias de arte e salas de concerto; Wilmington, por seu turno, era provinciana e acanhada. No decurso dos anos, com a prestação da DuPont, Wilmington cresceu e tornou-se um lugar interessante para viver.

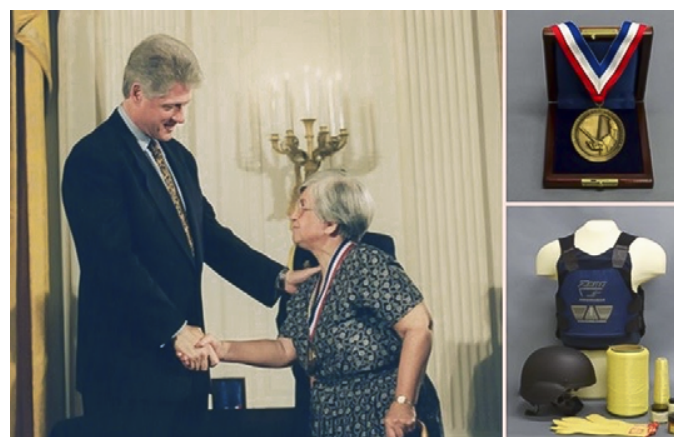

Figura 9 - Stephanie Kwolek recebe a National Medal of Technology das mãos
do Presidente Bill Clinton (1996).

Depois da descoberta do Kevlar, Kwolek continuou a criar outras fibras sintéticas. E nunca se arrependeu de se ter enamorado da química e abandonado a ideia da medicina.

Reformou-se após 40 anos ao serviço da DuPont. Dedicou-se à costura e à jardinagem, à preparação de palestras de incentivo ao estudo da ciência. De vez em quando, um polícia batia-Ihe à porta e dizia-Ihe: "O Kevlar salvou a minha vida". Kwolek sentia-se feliz por o destino a ter premiado com a descoberta de 
um produto que beneficiava outras pessoas. OrguIhava-se dos prémios que lhe tinham sido atribuídos. Faleceu em junho de 2014.

Stephanie Kwolek, em virtude da importância da descoberta da fibra Kevlar e do seu interesse industrial, recebeu o ACS Award for Creative Invention (1980) e a Lavoisier Medal atribuída pela DuPont (1995). No mesmo ano, o seu nome foi incluído na listagem National Inventors Hall of Fame (1995) e, dois anos depois, foi formalmente admitida no Plastics Hall of Fame (1997). Foi ainda premiada com a National Medal of Technology and Innovation, Química (1996), o IRI Achievement Award (1997) instituído pelo Industrial Research Institute, Inc. e a Perkin Medal (1997) da responsabilidade da Society of Chemical Industry (EUA), entre outros. Em 2003 integrou The National Women's Hall of Fame.

\section{Agradecimento}

Ao Hagley Museum and Library, que tão generosamente permitiu a reprodução de fotografias da sua formidável coleção de arquivo.

\section{Referências}

[1] Stephanie L. Kwolek, entrevista por Raymond C. Ferguson em Sharpley, Delaware, 4 maio 1986 (Philadelphia: Chemical Heritage Foundation, Ora History Transcript \# 0028). https://digital.sciencehistory.org/works/d217qq72t

[2] C. Howell, "Innovative Lives: Stephanie Kwolek and Kevlar ${ }^{\circledR}$, The Wonder Fiber", Lemerson Center, 1996. https://invention.si.edu/innovative-livesstephanie-kwolek-and-kevlar-wonder-fiber.

[3] W. Iwańczak, "Kobieta, Która zatrzymała pociski. Nowe fakty (A mulher que parou as balas. Novos factos)", Niedziela, n. 44 (2016). https://tzn.edu.pl/ static/uploaded/12a0cb5.pdf

[4] Stephen Kwolek terminou o curso de engenharia química na Universidade Carnegie Mellon após terminar a guerra para a qual fora destacado. Veio a integrar os laboratórios de investigação do Gulf Oil em Harmarville, Pensilvânia.

[5] Kwolek só em 1959 foi promovida a Research Chemist, em 1967 a Senior Research Chemist e, finalmente, a Research Associate em 1974. "As mulheres da minha geração tinham muita dificuldade em serem promovidas na DuPont...", afirmou Stephanie Kwolek [1].

[6] 0 Textile Fibers Department da DuPont foi instituído em 1936, sob a designação de Rayon Department. 0 novo nome surgiu em 1952, de forma a refletir a enorme variedade de fibras que iam sendo criadas. "Coleção "Dos Átomos e das Moléculas", vol. 7, Edições Colibri, Lisboa, 2019", Química 43 (2019) 50-55

[7] "I had just about all A's...", confidenciou Kwolek a R. C. Ferguson [1].

[8] R. Gonçalves-Maia, "Wallace Carothers - Nylon, a primeira fibra sintética; Neopreno, a primeira borracha sintética", Edições Colibri, Lisboa, 2019

\section{Raquel Gonçalves Maia}

É Professora Catedrática aposentada da FCUL. Desenvolveu atividade de investigação na área da Química-Física. Dirigiu o Boletim SPQ e integrou a Commission on Chemical Kinetics da IUPAC. Foi colaboradora regular do JL - Jornal de Letras, Artes e Ideias. A Química, a
História e a Filosofia das Ciências e a Literatura suscitaram o seu interesse. Tem centenas de artigos, 30 livros e alguns contos e romances publicados, em Portugal e no Brasil.

rmcgonc@gmail.com
[9] "Du Pont Textile Fibers Department Records, 1925-1970", Lemerson Center, 2014. https://invention.si.edu/du-pont-textile-fibers-department-records-1925-1970

[10] "Paul W. Morgan, 1911-1992", em "Memorial Tributes: National Academy of Engineering", vol. 7, 1994, 149-152. https://www.nap.edu/read/4779/chapter/31.

[11] D.A. Hounshell, J.K. Smith, Jr., "Science and Corporate Strategy: Du Pont R\&D, 1902-1980", Cambridge University Press, Nova lorque, 1995.

[12] Ao invés do cloreto de tereftaloilo pode usar-se o ácido tereftálico, com libertação de moléculas de água.

[13] C. Lefteri, "Materials for Design", Laurence King Publishing, Ltd, Londres, 2014.

[14] "Interview with Herbert Blades, 2014 August 19", History of Kevlar oral history interviews, Hagley Digital Archives. https://digital.hagley. org/2014249_20140819_Blades\#modal-close.

[15] S. L. Kwolek, "Optically Anisotropic Aromatic Polyamide Dopes," U.S. Patent 3,671,542, emitida em 20 de junho de 1972 (pedido apresentado em 23 de maio de 1969).

[16] S. L. Kwolek, "Wholly Aromatic Carbocyclic Polycarbonamide Fiber Having Orientation Angle of Less Than About 45 $5^{\circ}$, U.S. Patent 3,819,587, emitida em 25 de junho de 1974 (pedido apresentado em 7 de setembro de 1971).

[17] P.W. Morgan, S.L. Kwolek, "The nylon rope trick: Demonstration of condensation polymerization", J. Chem. Educ. 36 (1959) 182-184. 